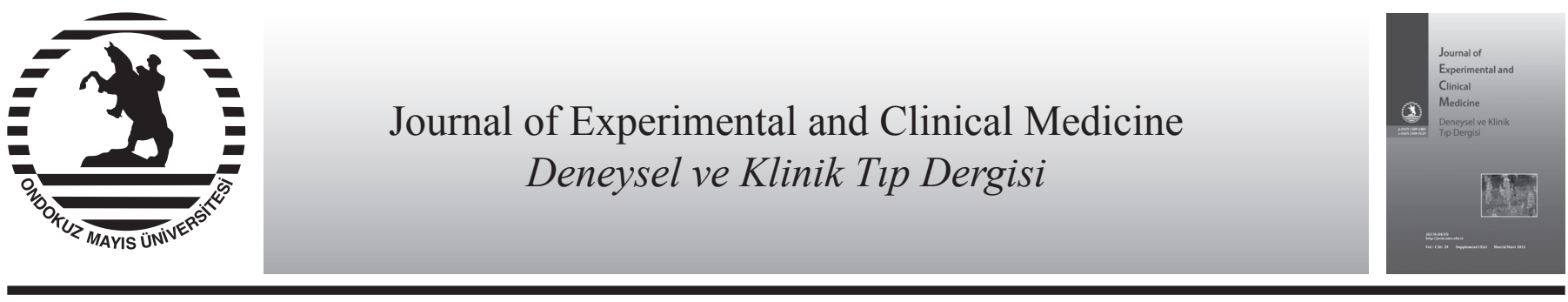

Derleme / Review

doi: $10.5835 /$ jecm.omu.29.s1.002

\title{
Diabetes mellitusun tanı ve izlem kriterleri
}

\section{Criteria for diagnosis and follow-up diabetes mellitus}

\author{
Ayşegül Atmaca* \\ Ondokuz Mayıs Üniversitesi, Tıp Fakültesi, Endokrinoloji ve Metabolizma Hastalıkları Bilim Dalı, Samsun, Türkiye
}

\begin{tabular}{|c|c|}
\hline MAKALE BİLGILERİ & ÖZET \\
\hline Makale geçmişi & \multirow{12}{*}{$\begin{array}{l}\text { Diabetes mellitus (DM); Tip } 1 \mathrm{DM} \text {, Tip } 2 \mathrm{DM} \text {, başka nedenlere bağl özel diyabet tipleri } \\
\text { ve gestasyonel DM olarak } 4 \text { gruba ayrılır. Açlık plazma glukozu (APG) } \geq 126 \mathrm{mg} / \mathrm{dL} \text {, } \\
75 \text { g oral glukoz tolerans testinin (OGTT) } 2 \text {. saatinde bakılan plazma glukozu } \geq 200 \mathrm{mg} / \\
\mathrm{dL} \text { veya HbA1C } \geq \% 6,5 \text { ise sonuçların bir kez daha doğrulanması koşuluyla DM tanıs1 } \\
\text { konabilir. Hiperglisemi semptomlarının varlığında rastgele bakılan plazma glukozunun } \\
\geq 200 \mathrm{mg} / \mathrm{dL} \text { olması da tanı koydurucudur. Bu durumda testin konfirme edilmesine gerek } \\
\text { yoktur. Gestasyonel DM için } 24-28 \text {. haftalarda yapılan } 75 \mathrm{~g} \text { OGTT'de APG } \geq 92 \mathrm{mg} / \mathrm{dL} \\
\text { veya } 1 . \text { saat plazma glukozu } \geq 180 \mathrm{mg} / \mathrm{dL} \text { veya } 2 \text {. saat plazma glukozu } \geq 153 \mathrm{mg} / \mathrm{dL} \text { olmas1 } \\
\text { tanı koydurucudur. DM tanısı alan gebe olmayan hastalarda glisemik kontrol hedefleri } \\
\text { HbA1C için }<\% 7 \text {, APG için } 70-130 \mathrm{mg} / \mathrm{dL} \text { ve tokluk plazma glukozu için }<180 \mathrm{mg} / \\
\text { dL'dir. Ancak bu hedefler DM süresi, hipoglisemi siklığ1, kardiyovasküler hastalık varlığ1 } \\
\text { ve yaşam beklentisi gibi faktörlere göre kişiselleştirilebilir. Gestasyonel DM'de glisemik } \\
\text { kontrol hedefleri ise; preprandiyal plazma glukozunun } \leq 95 \mathrm{mg} / \mathrm{dL} \text { ve } 1 . \text { saat postprandiyal } \\
\text { plazma glukozunun } \leq 140 \mathrm{mg} / \mathrm{dL} \text { veya } 2 \text {. saat postprandiyal plazma glukozunun } \leq 120 \mathrm{mg} / \\
\text { dL olmasıdır. }\end{array}$} \\
\hline Geliş $\quad 13 / 01 / 2011$ & \\
\hline 15 / 02 / 2011 & \\
\hline * Yazışma Adresi: & \\
\hline Ayşegül Atmaca & \\
\hline Ondokuz Mayıs Üniversitesi, & \\
\hline Tıp Fakültesi, & \\
\hline Endokrinoloji ve Metabolizma & \\
\hline Hastalıkları Bilim Dalı & \\
\hline Kurupelit/Samsun, Türkiye & \\
\hline e-posta: aysegulakin@yahoo.com & \\
\hline & \\
\hline Diabetes mellitus & J. Exp. Clin. Med., 2012; 29:S2-S6 \\
\hline
\end{tabular}

Glisemik kontrol

Sinıflandirma

İzlem kriterleri

Keywords:

Diabetes mellitus

Glycemic control

Classification

Follow-up criteria

\begin{abstract}
Diabetes mellitus (DM) is classified into 4 groups as Type 1 DM, Type 2 DM, other specific types of diabetes and gestational DM. Fasting plasma glucose (FPG) $\geq 126 \mathrm{mg} / \mathrm{dL}$, 2-hour plasma glucose during a $75 \mathrm{~g}$ oral glucose tolerance test (OGTT) $\geq 200 \mathrm{mg} / \mathrm{dL}$ and $\mathrm{HbA} 1 \mathrm{C} \geq 6.5 \%$ establishes the diagnosis of $\mathrm{DM}$, provided that the results are confirmed at another time. In a patient with classical symptoms of hyperglycemia, a random plasma glucose $\geq 200 \mathrm{mg} / \mathrm{dL}$ also establishes the diagnosis. In such a case, there is no need to confirm the diagnosis at another time. The diagnosis of gestational DM is made when any of the following criteria are met during a $75 \mathrm{~g}$ OGTT at 24-28 weeks of gestation: FPG $\geq 92 \mathrm{mg} / \mathrm{dL}$ or 1 -hour plasma glucose $\geq 180 \mathrm{mg} / \mathrm{dL}$ or 2 -hour plasma glucose $\geq 153$ $\mathrm{mg} / \mathrm{dL}$. HbA1C $<7 \%$, FPG 70-130 mg/dL and postprandial plasma glucose $<180 \mathrm{mg} / \mathrm{dL}$ are glycemic goals for nonpregnant adults. However, these goals may be individualized based on the duration of DM, occurence of hypoglycemia, presence of cardiovascular disease and life expectancy. Preprandial plasma glucose $\leq 95 \mathrm{mg} / \mathrm{dL}$ and 1-hour postprandial plasma glucose $\leq 140 \mathrm{mg} / \mathrm{dL}$ or 2-hour postprandial plasma glucose $\leq 120 \mathrm{mg} / \mathrm{dL}$ are glycemic goals for gestational DM.

J. Exp. Clin. Med., 2012; 29:S2-S6
\end{abstract}

\section{Giriş \\ Sinıflandırma ve tanı \\ Sinıflandırma}

Diabetes mellitus (DM) dört sınıfa ayrılır (Tablo 1):

1. Tip 1 DM: Beta hücre hasarına bağlı mutlak insülin eksikliği gelişir.

2. Tip 2 DM: İnsülin direnci zemininde ilerleyici pank- reas beta hücre hasarı ve insülin salınım defekti gelişir.

3. Diğer nedenlere bağlı özel DM tipleri: Beta hücre veya insülin fonksiyonundaki genetik defektler, endokrinopatiler, egzokrin pankreas hastalıkları, ilaca bağlı DM örnek olarak verilebilir.

4. Gestasyonel DM: İlk kez gebelik sırasında tanı konulan DM'dir. 


\section{Tablo 1. Diabetes mellitusun sinıflandırılması}

I.Tip 1 DM (Mutlak insülin eksikliğine yol açan beta hücre hasarı)

A. Otoimmün

B. İdyopatik

II. Tip 2 DM (İnsülin direncinin ön planda olduğu rölatif insülin eksikliği veya salınım defektinin ön planda olduğu insülin direnci)

\begin{tabular}{|c|c|c|c|c|}
\hline \multicolumn{5}{|c|}{ III. Diğer özel tipler } \\
\hline A. & & Beta hücre fonksiyonunun genetik defektleri & E. & İlaç veya kimyasal madde ile indüklenen \\
\hline & 1. & MODY 3 & & 1. Vakor \\
\hline & 2. & MODY 2 & & Pentamidin \\
\hline & 3. & MODY 1 & & Nikotinik asit \\
\hline & 4. & MODY 4 & & Glukokortikoidler \\
\hline & 5. & MODY 5 & & Tiroid hormonu \\
\hline & 6. & MODY 6 & & Diazoksit \\
\hline & 7. & Mitokondrial DNA & & Beta adrenerjik agonistler \\
\hline & 8. & Diğerleri & & Tiazidler \\
\hline B. & & İnsülin etkisinde genetik defektler & & Fenitoin \\
\hline & 1. & Tip A insülin direnci & & Alfa interferon \\
\hline & 2. & Leprekonizm & & Diğerleri \\
\hline & 3. & Rabson-Mendenhall sendromu & F. & Enfeksiyonlar \\
\hline & 4. & Lipoatrofik diyabet & & 1. Konjenital rubella \\
\hline & 5. & Diğerleri & & Sitomegalovirüs \\
\hline C. & & Egzokrin pankreas hastalıkları & & Diğgerleri \\
\hline & 1. & Pankreatit & G. & İmmün diyabetin nadir formları \\
\hline & 2. & Travma, pankreatektomi & & 1. Stiff-man sendromu \\
\hline & 3. & Neoplazi & & Anti-insülin reseptör antikorları \\
\hline & 4. & Kistik fibroz & & Diğerleri \\
\hline & 5. & Hemokromatozis & H. & Diyabetle ilişkili diğer genetik sendromlar \\
\hline & 6. & Fibrokalküloz pankreatopati & & Down sendromu \\
\hline & 7. & Diğerleri & & Klinefelter sendromu \\
\hline D. & & Endokrinopatiler & & Turner sendromu \\
\hline & 1. & Akromegali & & Wolfram sendromu \\
\hline & 2. & Cushing sendromu & & Friedreich ataksisi \\
\hline & 3. & Glukagonoma & & Huntington koresi \\
\hline & 4. & Feokromasitoma & & Laurence-Moon-Biedl sendromu \\
\hline & 5. & Hipertiroidizm & & Miyotonik distrofi \\
\hline & 6. & Somatostatinoma & & Porfiri \\
\hline & 7. & Aldosteronoma & & 10. Prader-Willi sendromu \\
\hline & 8. & Diğerleri & & Diğerleri \\
\hline
\end{tabular}

IV. Gestasyonel DM

$\mathrm{DM}=$ diabetes mellitus

MODY $=$ maturity onset diabetes of the young

\section{Tablo 2. Diabetes mellitusun tanı kriterleri}

$\mathrm{HbA1C} \geq \% 6,5$ (DCCT verilerine göre standardize edilmeli)* veya

Açlık plazma glukozu $\geq 126 \mathrm{mg} / \mathrm{dL}$ (açlık için en az 8 saat kalori alımı olmamalıdır)*

veya

75 g oral glukoz tolerans testinin 2. saatinde plazma glukozu $\geq 200 \mathrm{mg} / \mathrm{dL}^{*}$ veya

Hipergliseminin klasik semptomları olan veya hiperglisemik krizde olan bir kişide rasgele plazma glukozu $\geq 200 \mathrm{mg} / \mathrm{dL}$

* Test sonuçları aynı test veya başka bir testle konfirme edilmelidir. DCCT $=$ Diabetes Control and Complications Trial

Bazı hastalarda Tip 1 ve Tip 2 DM ayrımı yapmak zor olabilir. Tip 2 DM'nin ilk prezentasyonu ketoasidozla olabileceği gibi, geç başlayan ve yavaş ilerleyen tip $1 \mathrm{DM}$ tipleri de vardır. Bu durumlarda klinik zaman içinde belirginleşir ve tanı da o zaman netleşir.

\section{Tanı}

Uzun yıllardır DM tanısı açlık plazma glukozu (APG) ve 2 saatlik $75 \mathrm{~g}$ oral glukoz tolerans testi (OGTT) ile konurken 2009 y1lında Amerikan Diyabet Cemiyeti (ADA), Uluslararası Diyabet Federasyonu (IDF) ve Avrupa Diyabet
Çalışma Birliği (EASD) HbA1C'nin tanıda kullanılmasını önermişlerdir (International Expert Committee, 2009). HbA1C $\geq \% 6,5$, DM tanısı için eşik değer kabul edilmiştir (ADA, 2010). HbA1C'nin tanı kriteri olarak kabul edilmesi, APG ve OGTT'ye benzer şekilde HbA1C'nin retinopati gelişimi ile korele olduğunun epidemiyolojik çalışmalarda gösterilmesi sonucu olmuştur. HbA1C'nin APG ve OGTT'ye bazı üstünlükleri vardır:

1. Açlik gerektirmez.

2. Preanalitik stabilitesi daha fazladir.

3.Akut hastalık ve stres durumlarında düzeyleri değişkenlik göstermez.

Ancak daha pahalıdır, plazma glukoz ölçümleri kadar yaygın değildir, kan kaybı, hemoliz, gebelik, hemoglobinopatiler ve anemilerden etkilenir, etnik kökene göre normal aralıkları değişkenlik gösterebilir. Ayrıca glisemik değişkenliği olan hastalarda sonuçlar normal gelebilir.

DM için öngörülen yeni tanı kriterleri Tablo 2'de gösterilmiştir. HbA1C ölçümü ile APG veya OGTT sonuçları arasında her zaman uyum olmayabilir. Bir test ile DM tanısı konduktan sonra laboratuvar hatasını dışlamak için test tekrarlanmalı veya diğer bir testle doğrulanmalıdır. Tercih edilen aynı testin tekrarlanmasıdır. Ancak belirgin DM kliniği varlığında rastgele plazma glukozunun $\geq 200 \mathrm{mg} / \mathrm{dL}$ ölçül- 
mesi durumunda test tekrarına gerek yoktur. Hastaya iki farklı test yapılmışsa, sonucu yüksek olan test tekrarlanmalıdır. İlk testin tanı kriterlerinin üstünde, ikinci testin ise altında olması durumunda test 3-6 ay sonra tekrarlanmalıdır (ADA, 2011).

APG 100-125 mg/dl arası (bozulmuş açlık glukozu BAG) ve 2 saatlik 75 g OGTT sonrası 2. saat plazma glukozu 140-199 mg/dl arası (bozulmuş glukoz toleransı-BGT) prediyabet olarak adlandırılır. Prediyabet; dislipidemi, hipertansiyon ve obezite ile yakın ilişkilidir. Ayrıca DM ve kardiyovasküler hastalık açısından risk faktörüdür. Yapılan çalışmalarda HbA1C düzeyi arttıkça DM gelişme riskinin de arttığı gösterilmiştir (Selvin ve ark., 2010; Zhang ve ark., 2010). Bu nedenle HbA1C, \%5,7-6,4 arasındaki değerler prediyabet olarak kabul edilmiştir (ADA, 2010; ADA 2011).

Asemptomatik kişilerde aşağıdaki durumlarda DM taraması yapılmalıdır (ADA, 2011):

1. Beden kitle indeksi $\geq 25 \mathrm{~kg} / \mathrm{m}^{2}$ olan ve aşağıdaki risk faktörlerinden birine sahip olan tüm erişkinlere:

- Fiziksel olarak inaktif kişiler

- Birinci derece akrabada DM olmas1

- Etnik köken olarak yüksek riskli grupta olmak

- Makrozomik bebek öyküsü (>4500 g) veya gestasyonel DM öyküsü

- Hipertansiyon $(\geq 140 / 90 \mathrm{mmHg})$ veya antihipertansif tedavi alıyor olmak

- HDL kolesterol $<35 \mathrm{mg} / \mathrm{dL}$ veya trigliserit $>250 \mathrm{mg} / \mathrm{dL}$

- Polikistik over sendromu olan kadınlar

- Önceki testte $\mathrm{HbA} 1 \mathrm{C} \geq \%$ 5,7, BAG veya BGT olmas1

- İnsülin direnciyle ilişkili durumlar (ciddi obezite, akantosis nigrikans gibi)

2. Yukarıdaki kriterlerden hiçbiri yoksa tarama 45 yaşında başlamalıdır.

3. Sonuçlar normalse tarama 3 yılda bir tekrarlanmalıdır. Ancak başlangıç test sonuçları ve risk faktörlerine göre daha sık aralıklarla da yapılabilir. Tip 1 DM için rutin tarama önerilmemektedir. Ancak bazı yüksek riskli kişilerde (daha önceden geçici hiperglisemisi olan veya Tip 1 DM'li akrabası olanlar gibi) otoantikor bakmak uygun olabilir.

Gebelikte tanı konmamış Tip 2 DM'i dişlamak için yukarıda sayılan risk faktörleri olan kadınlara ilk prenatal vizitte standart testlerle tarama yapılmalıdır. $\mathrm{Bu}$ vizitte standart testlerle yapılan taramada tanı kriterleri yukarıda sayılan kriterlerle aynıdır. Test sonuçları DM ile uyumlu olduğu takdirde bu aşikar, non-gestasyonel DM olarak kabul edilmelidir.

Gestasyonel DM hem anne, hem de bebek için yüksek riskli bir durumdur. The Hyperglycemia and Adverse Pregnancy Outcomes (HAPO) çalışmasında 25000 gebe kadın taranmış, hipergliseminin 24-28. haftalardan sonra anne ve bebek için eski kriterlere göre normal kabul edilen değerlerde bile riskli olduğu gösterilmiştir (HAPO Study Cooperative Research Group, 2008). Bu çalışmanın sonuçlarına göre ADA'nın temsilcilerinin de içinde bulunduğu Uluslararası Diyabet ve Gebelik Çalışma Grupları Birliği (IADPSG) yeni gestasyonel DM kriterlerini belirlemiştir (International Association of Diabetes and Pregnancy Study Groups Consensus Panel, 2010). Buna göre daha önce DM tanısı almamış gebe kadınların 24-28. haftalarda 8 saatlik açlığı takiben sabah 75 g OGTT ile taranması önerilmiştir. Tanı aşağıdaki kriterlerden bir tanesinin pozitif olması ile konur:

- $\mathrm{APG} \geq 92 \mathrm{mg} / \mathrm{dL}$
- 1. saat $P G \geq 180 \mathrm{mg} / \mathrm{dL}$

- 2. saat $P G \geq 153 \mathrm{mg} / \mathrm{dL}$

Gestasyonel DM tanısı alan bir kadında önceden var olan DM kesin olarak dışlanamayacağı için postpartum 6-12. haftalarda gebe olmayanlarda kullanılan kriterlere göre OGTT ile taranmalıdir.

\section{3. İzlem}

\section{İzlem kriterleri}

İlk değerlendirmede DM'in tipi, daha önce verilen tedaviler, glisemik kontrol, komplikasyonlar ve tedavi planı açısından ayrıntılı öykü alınmalı ve fizik muayene yapılmalıdır. Öyküde; yaş, DM'in başlangıç şekli, yeme alışkanlıkları, yaşam tarzı, daha önceden aldığı tedaviler, glisemik kontrol düzeyi, diyabetin akut komplikasyonları, hipoglisemi, kronik komplikasyonlar (nefropati, retinopati, nöropati, koroner arter hastalığı, serebrovasküler hastalık, periferik arter hastalığ 1 ) ile ilgili belirti ve bulgular ayrıntılı sorulmalıdır. Fizik muayenede tüm sistemik muayene yapılmalıdır. Ancak boy, kilo, beden kitle indeksi, kan basıncı, ortostatik hipotansiyon varlığı, göz dibi muayenesi, tiroid muayenesi, cilt muayanesi (akantozis nigrikans, insülin enjeksiyon bölgeleri), ayak muayenesi (inspeksiyon, dorsalis pedis ve tibialis posterior nabızları, patellar ve aşil refleksleri, propriosepsiyon, vibrasyon ve monofilaman duyusu) DM'de özellikle dikkatle yapılması gereken muayenelerdir.

$\mathrm{HbA1C}$ son 2-3 ay içinde bakılmadıysa mutlaka istenmelidir. Ayrıca son 1 yıl içinde bakılmadıysa açlık lipid profili (total kolesterol, LDL kolesterol, HDL kolesterol ve trigliseritler), karaciğer fonksiyon testleri, idrar albümini (spot idrarda albümin kreatinin oranı), serum kreatinini, glomerüler filtrasyon hızı bakılmalıdır. Testleri normal olan hastalarda bu testler yılda bir kez tekrarlanmalıdır. Ayrıca Tip 1 DM'li hastalarda, dislipidemisi olanlarda ve 50 yaşın üstündeki kadın hastalarda tiroid stimülan hormon (TSH) düzeylerine de bakılmalıdır (ADA, 2011).

Yılda bir kez göz dibi değerlendirmesi yapılmalıdır. Diş sağlığı ve diş eti hastalıkları gözden geçirilmelidir. Hastalar gerekli görüldüğü takdirde mental sağlık ve psikolojik sorunlar açısından da değerlendirilmelidir. Reprodüktif çağdaki kadınlara doğum kontrol yöntemleri hakkında bilgi verilmelidir. Hastalara eğitim verilmeli ve tıbbi nütrisyon tedavisi planlanmalıdır. DM'li hastalar; konusunda uzman bir hekim, diyabet hemşiresi, diyetisyen ve komplikasyonlar geliştiği takdirde ilgili bölümlerce ekip halinde izlenmelidir.

\section{Glisemik kontrol}

DM'li hastaların izleminde hastanın kendi kendine monitorize ettiği kan şekerlerinin ve HbA1C'nin ayrı ayrı önemi vardir.

\section{Kan şekeri monitorizasyonu}

Multipl enjeksiyon yapan veya insülin pompası (özellikle Tip 1 DM'li hastalar ve gebeler) kullanan hastalarda hasta günde 4 kez kan şekerini ölçmelidir. Diğer tedavi yöntemlerini kullanan hastalarda da kendi kendine monitorizasyon glisemik kontrol açısından önemlidir ancak monitorizasyon sıklığı konusunda görüş birliği yoktur. $\mathrm{Bu}$ amaçla hem açlik, hem tokluk plazma glukozu bakılabilir. Yirmibeş yaşın üstünde, intensif insülin tedavisi alan Tip 1 DM'li hastalarda sürekli glukoz monitorizasyonu tedaviyi yönlendirmede önemlidir. Sürekli glukoz monitorizasyonu sık hipoglisemisi olanlarda 
ve hipoglisemiyi fark edemeyenlerde de önerilmektedir. Kendi kendine monitorizasyon, kan şekeri ölçüm aletine bağımlı olduğu için hastalar bu konuda eğitilmeli ve belli aralıklarla ölçüm aletinin kontrolü yapılmalıdır.

\section{HbA1C}

HbA1C ölçümleri 3 ayda bir yapılmalıdr. Özellikle tedavi değişikliği yapılan ve glisemik hedeflere ulaşılamayan hastalarda 3 ayda bir ölçümler önemlidir. Tedavi hedeflerine ulaşan ve stabil glisemik kontrolü olan hastalarda ise y1lda 2 kez yapılabilir (ADA, 2011). HbA1C ortalama plazma glukozunun güvenilir bir göstergesidir. Ancak hastanın klinik durumuyla HbA1C'nin korele olmadığ binopatiler, hemoliz, kan kaybı gibi durumlar düşünülmelidir (Sacks ve ark., 2002). Ayrıca glisemik değişkenliği olan hastalarda $\mathrm{HbA} 1 \mathrm{C}$ hedefte veya hedefe yakın olabilir. Bu durumlarda $\mathrm{HbA} 1 \mathrm{C}$ ve kendi kendine kan şekeri monitorizasyon sonuçlarını birlikte değerlendirmek gerekir. Fruktozamin de kronik gliseminin bir göstergesidir ancak HbA1C kadar güvenilir değildir.

\section{Glisemik hedefler}

DM'de glisemik kontrolün önemi hem DCCT, hem de UKPDS çalışmalarında gösterilmişitir (DCCT; 1993; UKPDS,1998). Bu çalışmalarda intensif glisemik kontrolün mikrovasküler ve nöropatik komplikasyonları azalttığı gösterilmiştir. Her iki çalışma sonlandırıldıktan sonra hastalar standart takip edilmiş, intensif tedavi gruplarındaki faydanın standart tedaviyle devam edilse bile yıllar boyu sürdüğü gösterilmiştir (DCCT-EDIC, 2000; Martin ve ark., 2006; Holman ve ark., 2008). Yakın dönemde tamamlanan ACCORD, ADVANCE ve VADT çalışmalarında da, uzun süreli Tip 2 DM'i olan hastaların intensif tedavi ile mikrovasküler komplikasyonlardan korunduğu gösterilmiştir (Action to Control Cardiovascular Risk in Diabetes Study Group, 2008; ADVANCE Colloborative Group, 2008; Duckworth ve ark., 2009). Ancak ACCORD çalışması, intensif tedavi ile artmış mortalite nedeniyle erken sonlandırılmıştır. İntensif glisemik kontrolün hipoglisemiye yol açacağı ve bunun da kardiyovasküler olayları tetikleyeceği düşünülürse uzun süreli DM'i olan, kardiyovasküler hastalığı olan ve yaşam beklentisi kısa olan hastalarda intensif kontrol uygun olmayabilir.

İntensif glisemik kontrolün mikrovasküler komplikasyonlar üzerine etkisi daha net gösterilmekle birlikte kardiyovasküler olaylar üzerine etkisi tartışmalıdır. DCCT çalışmasında intensif kontrolle kardiyovasküler olaylarda azalma eğilimi gözlenmiştir. DCCT-EDIC takip çalışmasında ise intensif tedavi grubunda çalışma sonlandırıldıktan sonra uzun dönemde de ölümcül olmayan miyokard enfarktüsü, inme ve kardiyovasküler ölümlerin anlamlı derecede az olduğu gözlenmiştir (Nathan ve ark., 2005). UKPDS çalışmasında da intensif tedavi grubunda ölümcül olan ve olmayan miyokard enfarktüsü ve ani ölüm daha az görülmüş ancak istatistiksel olarak anlamlı bulunmamıştır (UKPDS, 1998). Çalışma sonlandıktan sonra hastalar uzun dönem takip edildiğinde, daha önce intensif tedavi alan grupta miyokard enfarktüsü ve tüm nedenlere bağlı ölümlerde istatistiksel olarak anlamlı derecede azalma gözlenmiştir (Holman ve ark., 2008). ACCORD, ADVANCE ve VADT çalışmalarına alınan hastalar UKPDS'ye göre DM'u daha ilerlemiş olan hastalardı. Bu çalışmalarda intensif glisemik kontrol kardiyovasküler sonlanım noktalarında anlamlı azalmaya yol açmadığ 1 gösterilmiştir. ACCORD çalışmasında ise intensif grupta mortalite daha yüksek bulunduğu için çalışma erken sonlandırılmıştır (Action to Control Cardiovascular Risk in Diabetes Study Group, 2008). Artmıss mortalite nedeni net olarak ortaya konamamış, ancak, subgrup analizleri yapıldığında HbA1c değeri başlangıçta yüksek olan hastaların mortalitesi daha yüksek bulunmuştur.

UKPDS' de yeni tanı DM'li hastalar çalışmaya alınırken; ACCORD, ADVANCE ve VADT çalışmalarında 8-11 yıllık DM'i olan, kardiyovasküler hastalığı veya risk faktörleri olan, dolayısıyla yerleşmiş ateroskelorozu olan hastalar alınmıştır. Bu üç çalışmanın subgrup analizlerinde intensif tedaviden fayda gören hastalar daha kısa süreli DM'i olan, başlangıçta daha düşük HbA1C'si olan ve bilinen kardiyovasküler hastalığı olmayan hastalardı. Bu bilgiler 1şığında ADA'nın gebe olmayan erişkinlerde glisemik kontrol için önerileri aşağıdaki gibi özetlenebilir (ADA, 2011):

1. HbA1C'yi <\%7'ye düşürmek mikrovasküler ve nöropatik komplikasyonları azaltır. İntensif kontrol tanıdan hemen sonra başlanırsa makrovasküler hastalık riski de azalır.

2. Diyabet süresi kısa olan, yaşam beklentisi uzun olan ve kardiyovasküler hastalığı olmayanlarda daha düşük HbA1C düzeyleri hedeflenebilir.

3. Yaşam beklentisi kısa olan, ciddi hipoglisemisi olan, ilerlemiş mikrovasküler ve makrovasküler komplikasyonları ve komorbid durumları olan hastalarda $\mathrm{HbA1C}$ hedefi daha yüksek tutulabilir.

4. HbA1C $<\% 7$ düzeyi ile korele preprandiyal ve postprandiyal kapiller plazma glukoz hedefleri sirasiyla 70-130 $\mathrm{mg} / \mathrm{dl}$ ve $<180 \mathrm{mg} / \mathrm{dL}$ 'dir.

Bazı çalışmalarda postprandiyal glukozun preprandiyal glukoza göre kardiyovasküler riski daha çok predikte ettiği gösterilmiştir. Ancak DCCT ve UKPDS gibi çalışmalarda glisemik kontrol belirleyicileri olarak $\mathrm{HbA1c}$ ve preprandiyal ölçümler esas alınmıştır. Postprandiyal ölçümler, preprandiyal glukoz değerleri hedefte olup da HbA1C'si hedefe ulaşamayan hastalarda yapılabilir.

Gestasyonel DM'de maternal kapiller glukoz hedefleri ise Beşinci Uluslararası Gestasyonel Diyabet Konferansı'nda aşağıdaki gibi belirlenmiştir (Metzger ve ark., 2007):

- Preprandiyal $\leq 95 \mathrm{mg} / \mathrm{dL}$ ve

- 1. saat postprandiyal $\leq 140 \mathrm{mg} / \mathrm{dL}$ veya

- 2. Saat postprandiyal $\leq 120 \mathrm{mg} / \mathrm{dL}$

Önceden bilinen Tip 1 veya Tip 2 DM'i olan gebelerde ise hipoglisemiden kaçınmak koşuluyla aşağıdaki hedefler önerilmektedir (Kitzmiller ve ark., 2008):

- Preprandiyal, gece yatarken ve gece glukozu 60-99 mg/dl

- Postprandiyal glukoz 100-129 mg/dL

- HbA1c $<\% 6$

\section{KAYNAKLAR}

ADVANCE Colloborative Group, Patel, A., MacMahon, S., Chalmers, J., Neal, B., Billot, L., Oodward, M., Marre, M., Cooper, M., Glasziou, P., Grobbee, D., Hamet, P., Harrap, S., Heller, S., Liu, L., Mancia, G., Mogensen, C.E., Pan, C., Poulter, N., Rodgers, A., Williams, B., Bompoint, S., De Galan, B.E., Joshi, R., Travert, F., 2008. Intensive blood glucose control and vascular outcomes in patients with type 2 diabetes. 
N. Engl. J. Med. 358, 2560-2572.

American Diabetes Association, 2010. Diagnosis and classification of diabetes mellitus. Diabetes Care 33 Suppl. 1, S62-S69.

American Diabetes Association, 2011. Standards of medical care in diabetes-2011. Diabetes Care 34 Suppl. 1, S11-S61.

DCCT, 1993. The effect of intensive treatment of diabetes on the development and progression of long-term complications in insulin-dependent diabetes mellitus. The Diabetes Control and Complications Trial Research Group, N. Engl. J. Med. 329, 977-986.

DCCT-EDIC, 2000. Retinopathy and nephropathy in patients with type 1 diabetes four years after a trial of intensive therapy. The Diabetes Control and Complications Trial/Epidemiology of Diabetes Interventions and Complications Research Group. N. Engl. J. Med. 342, $381-389$.

Duckworth, W., Abraira, C., Moritz, T., Reda, D., Emanuele, N., Reaven, P.D., Zieve, F.J., Marks, J., Davis, S.N., Hayward, R., Warren, S.R., Goldman, S., McCarren, M., Vitek, M.E., Henderson, W.G., Huang, G.D., VADT Investigators, 2009. Glucose control and vascular complications in veterans with type 2 diabetes. N. Engl. J. Med. 360, 129-139.

Gerstein, H.C., Miller, M.E., Byington, R.P., Goff, D.J. Jr, Bigger, J.T., Buse, J.B., Cushman, W.C., Genuth, S., Ismail-Beigi, F., Grimm, R.H. Jr, Probstfield, J.L., Simons-Morton, D.G., Friedewald, W.T., 2008. Action to control cardiovascular risk in diabetes. Effects of intensive glucose lowering in type 2 diabetes. N. Engl. J. Med. 358, 2545-2559.

HAPO Study Cooperative Research Group, Metzger, B.E., Lowe, L.P., Dyer, A.R., Trimble, E.R., Chaovarindr, U., Coustan, D.R., Hadden, D.R., McCance, D.R., Hod, M., McIntyre, H.D., Oats, J.J., Persson, B., Rogers, M.S., Sacks, D.A., 2008. Hyperglycemia and adverse pregnancy outcomes. N. Engl. J. Med. 358, 1991-2002.

Holman, R.R., Paul S.K., Bethel, M.A., Matthews, D.R., Neil, H.A., 2008. 10-year follow-up of intensive glucose control in type 2 diabetes. N. Engl. J. Med. 359, 1577-1589.

International Association of Diabetes and Pregnancy Study Groups Consensus Panel, Metzger, B.E., Gabbe, S.G., Persson, B., Buchanan, T.A., Catalano, P.A., Damm, P., Dyer, A.R., Leiva, A., Hod, M., Kitzmiler, J.L., Lowe, L.P., McIntyre, H.D., Oats, J.J., Omori, Y., Schmidt, M.I., 2010. International association of diabetes and pregnancy study groups recommendations on the diagnosis and classification of hyperglycemia in pregnancy. Diabetes Care 33, 676-682.

International Expert Committee, 2009. International Expert Committee report on the role of the A1C assay in the diagnosis of diabetes. Diabetes Care 32, 1327-1334.

Kitzmiller, J.L., Block, J.M., Brown, F.M., Catalano, P.M., Conway, D.L., Coustan, D.R., Gunderson, E.P., Herman, W.H., Hoffman, L.D., Inturrisi, M., Jovanovic, L.B., Kjos, S.I., Knopp, R.H., Montoro, M.N., Ogata, E.S., Paramsothy, P., Reader, D.M., Rosenn, B.M., Thomas, A.M., Kirkman, M.S., 2008. Managing preexisting diabetes for pregnancy: summary of evidence and consensus recommendations for care. Diabetes Care 31, 1060-1079.

Martin, C.L., Albers, J., Herman, W.H., Cleary, P., Waberski, B., Greene, D.A., Stevens, M.J., Feldman, E.L., DCCT/EDIC Research Group, 2006. Neuropathy among the diabetes control and complications trial cohort 8 years after trial completion. Diabetes Care 29, 340-344.

Metzger, B.E., Buchanan, T.A., Coustan, D.R., De Leiva, A., Dunger, D.B., Hadden, D.R., Hod, M., Kitzmiller, J.L., Kjos, S.L., Oats, J.N., Pettitt, D.J., Sacks, D.A., Zoupas, C., 2007. Summary and recommendations of the Fifth International Workshop-Conference on Gestational Diabetes Mellitus. Diabetes Care 30 Suppl.2, S251-S260.

Nathan, D.M., Cleary, P.A., Backlund, J.Y., Genuth, S.M., Lachin, J.M., Orchard, T.J., Raskin, P., Zinman, B., Diabetes Control and Complications Trial/Epidemiology of Diabetes Interventions and Complications (DCCT/EDIC) Study Research Group, 2005. Intensive diabetes treatment and cardiovascular disease in patients with type 1 diabetes. N. Engl. J. Med. 353, 2643-2653.

Sacks, D.B., Bruns, D.E., Goldstein, D.E., Maclaren, N.K., McDonald, J.M., Parrott, M., 2002. Guidelines and recommendations for laboratory analysis in the diagnosis and management of diabetes mellitus. Clin. Chem. 48, 436-472.

Selvin, E., Steffes, M.W., Zhu, H,. Matsushita, K., Wagenknecht, L., Pankow, J., Coresh, J., Brancati, F.L., 2010. Glycated hemoglobin, diabetes, and cardiovascular risk in nondiabetic adults. N. Engl. J. Med. 362, 800-811.

UKPDS,1998. Intensive blood-glucose control with sulphonylureas or insulin compared with conventional treatment and risk of complications in patients with type 2 diabetes (UKPDS 33). UK Prospective Diabetes Study (UKPDS) Group. Lancet 352, 837-853.

Zhang, X., Gregg, E.W., Williamson, D.F., Barker, L.E., Thomas, W., Bullard, K.M., Imperatore, G., Williams, D.E., Albright, A.L., 2010. A1C level and future risk of diabetes: A systematic review. Diabetes Care 33, 1665-1673. 